However, it should be suspected in patients with cardiogenic shock and pulmonary edema in the presence of atrial fibrillation and mitral valve disease, especially mitral stenosis. In our patient, previous mitral stenosis was aggravated by a thrombus penetrating the left ventricle, which caused mechanical mitral insufficiency. Surgical removal of the thrombi with simultaneous treatment of the underlying cause, in this case replacement of the mitral valve, and subsequent anticoagulation is the therapy of choice. ${ }^{4,5}$

\section{References}

1. Noji Y, Kojima T, Aoyama T, Yamaguchi M, Araki T, Fujino S, et al. Free-floating thrombus in right heart and massive pulmonary embolism migrating into pulmonary artery. Circulation. 2005;111:e438-9.

2. Leung D, Davidson P, Cranney G, Walsh W. Thromboembolic risks of left atrial thrombus detected by transesophageal echocardiogram. Am J Cardiol. 1997;79: 626-9.

3. Tornoczky T, Ajtay Z. Images in clinical medicine. Fatal free-floating left atrial thrombus. NEJM. 2004;351:e25.

4. Tsioufis CP, Stefanadis CI, Tsiamis EG, Kallikazaros IE, Toutouzas PK. A free floating ball thrombus in the left atrial cavity. J Thorac Cardiovasc Surg. 1999;118:1120-2.

5. Grandmougin D, Letourneau T, Favre JP, Barral X. Paroxysmal postural dyspnea related to a left atrial ball thrombus. Ann Thorac Surg. 2002;74:1691-4.

\title{
Patients with truncus arteriosus do not have a patent arterial duct: True or false?
}

\author{
Luca A. Vricella, MD, FACS, and Duke E. Cameron, MD, Baltimore, Md
}

It is commonly believed that in the absence of aortic arch interruption, ${ }^{1}$ neonates given diagnoses of truncus arteriosus (or common arterial trunk [CAT]) should not have coexistence of a patent ductus arteriosus (PDA). Simultaneous presence of a PDA and CAT has been reported with extreme rarity. ${ }^{2}$ Figure 1 shows an intraoperative photograph taken during the complete repair of a $3.4-\mathrm{kg}$ newborn with type II CAT (Collett and Edwards classification ${ }^{3}$ ). The right and left branch pulmonary arteries are retracted on snares, and between their respective origins from the arterial trunk, a PDA is seen joining the pulmonary arterial confluence and the uninterrupted aortic isthmus.

In the 1976 classic article describing clinical, angiocardiographic, and pathologic findings in 100 patients with CAT, ${ }^{3}$ a PDA was observed in 14 patients. Among these, aortic arch interruption and anomalous ductal origin of the pulmonary artery were present in 10 and 2 patients, respectively. A PDA was well documented in only $2 \%$ of patients without the above-mentioned associated anomalies.

\section{References}

1. Konstantinov IE, Karamlou T, Blackstone EH, Mosca RS, Lofland GK, Caldarone CA, et al. Truncus arteriosus associated with interrupted aortic arch in 50 neonates: a Congenital Heart Surgeons Society Study. Ann Thorac Surg. 2006;81:214-23.

From the Division of Cardiac Surgery, The Johns Hopkins Medical Institutions, Baltimore, Md.

Received for publication Nov 3, 2007; accepted for publication Dec 16, 2007.

Address for reprints: Luca A. Vricella, MD, FACS, Division of Cardiac Surgery, The Johns Hopkins Hospital, $600 \mathrm{~N}$ Wolfe St-Blalock 618, Baltimore, MD, 21287 (E-mail: lvricella@jhmi.edu).

J Thorac Cardiovasc Surg 2008;136:1376

$0022-5223 / \$ 34.00$

Copyright (c) 2008 by The American Association for Thoracic Surgery doi:10.1016/j.jtcvs.2007.12.048

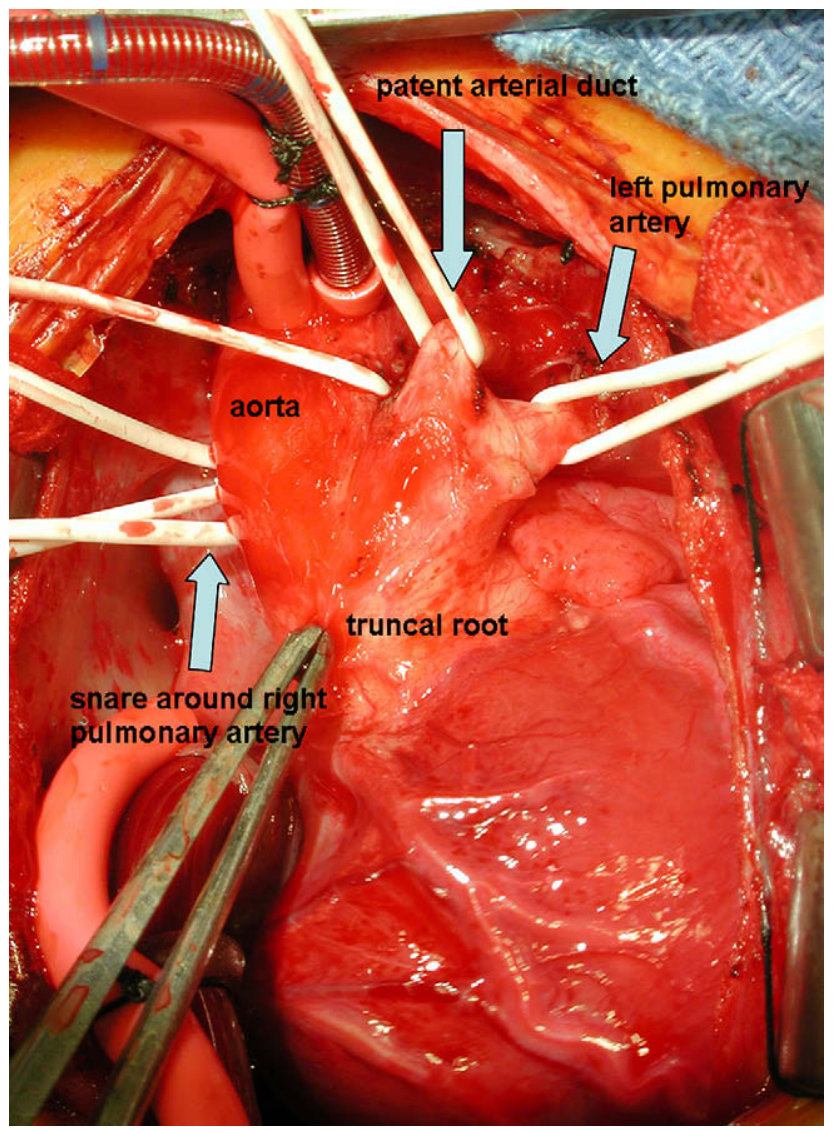

FIGURE 1. Intraoperative photograph of a newborn with type II CAT.

2. Collett RW, Edwards JE. Persistent truncus arteriosus; a classification according to anatomic types. Surg Clin North Am. 1949;29:1245-69.

3. Calder L, Van Praagh RV, Van Praagh S, Sears WP, Corwin R, Levy A, et al. Clinical, angiocardiographic, and pathologic findings in 100 patients. Am Heart J. 1976;92:23-38. 